\title{
Sleep Deprivation Selectively Upregulates an Amygdala-Hypothalamic Circuit Involved in Food Reward
}

\author{
이uia S. Rihm, ${ }^{1}{ }^{\oplus}$ Mareike M. Menz, ${ }^{1}$ Heidrun Schultz, ${ }^{2}$ Luca Bruder, ${ }^{3}$ Leonhard Schilbach,,${ }^{4}$ Sebastian M. Schmid, ${ }^{5}$ \\ and Jan Peters ${ }^{3}$ \\ ${ }^{1}$ Department for Systems Neuroscience, University Medical Center Hamburg-Eppendorf, Hamburg 20246, Germany, ${ }^{2}$ School of Psychology, University of \\ Birmingham, Birmingham B15 2TT, United Kingdom, ${ }^{3}$ Department of Psychology, Biological Psychology, University of Cologne, Cologne 50969, Germany, \\ ${ }^{4}$ Independent Max Planck Research Group for Social Neuroscience, Max Planck Institute for Psychiatry, Munich 80804, Germany, and ${ }^{5}$ Department of \\ Internal Medicine I, Section of Endocrinology and Diabetes, University Hospital Schleswig-Holstein, Luebeck 23562, Germany
}

Sleep loss is associated with increased obesity risk, as demonstrated by correlations between sleep duration and change in body mass index or body fat percentage. Whereas previous studies linked this weight gain to disturbed endocrine parameters after sleep deprivation or restriction, neuroimaging studies revealed upregulated neural processing of food rewards after sleep loss in reward-processing areas such as the anterior cingulate cortex, ventral striatum, and insula. To address this ongoing debate between hormonal versus hedonic factors underlying sleep-loss-associated weight gain, we rigorously tested the association between sleep deprivation and food cue processing using high-resolution fMRI and assessment of hormones. After taking blood samples from 32 lean, healthy, human male participants, they underwent fMRI while performing a neuroeconomic, value-based decision-making task with snack food and trinket rewards following a full night of habitual sleep and a night of sleep deprivation in a repeated-measures crossover design. We found that des-acyl ghrelin concentrations were increased after sleep deprivation compared with habitual sleep. Despite similar hunger ratings due to fasting in both conditions, participants were willing to spend more money on food items only after sleep deprivation. Furthermore, fMRI data paralleled this behavioral finding, revealing a food-reward-specific upregulation of hypothalamic valuation signals and amygdalahypothalamic coupling after a single night of sleep deprivation. Behavioral and fMRI results were not significantly correlated with changes in acyl, des-acyl, or total ghrelin concentrations. Our results suggest that increased food valuation after sleep loss might be due to hedonic rather than hormonal mechanisms.

Key words: decision making; food intake; hypothalamus; obesity; reward; sleep deprivation

\section{Significance Statement}

Epidemiological studies suggest an association between overweight and reduced nocturnal sleep, but the relative contributions of hedonic and hormonal factors to overeating after sleep loss are a matter of ongoing controversy. Here, we tested the association between sleep deprivation and food cue processing in a repeated-measures crossover design using fMRI. We found that willingness to pay increased for food items only after sleep deprivation. fMRI data paralleled this behavioral finding, revealing a foodreward-specific upregulation of hypothalamic valuation signals and amygdala-hypothalamic coupling after a single night of sleep deprivation. However, there was no evidence for hormonal modulations of behavioral or fMRI findings. Our results suggest that increased food valuation after sleep loss is due to hedonic rather than hormonal mechanisms.

\section{Introduction}

Numerous epidemiological studies suggest a link between reduced nocturnal sleep and increased risk for overweight and obe-

Received Jan. 29, 2018; revised Sept. 18, 2018; accepted 0ct. 15, 2018.

Author contributions: J.S.R., H.S., S.M.S., and J.P. edited the paper; J.P. wrote the first draft of the paper. J.S.R., L.S., and J.P. designed research; J.S.R. and M.M.M. performed research; H.S. and S.M.S. contributed unpublished reagents/analytic tools; J.S.R., L.B., and J.P. analyzed data; J.S.R. and J.P. wrote the paper.

This work was supported by the Deutsche Forschungsgemeinschaft (TR CRC 134, Project C05 to J.P. and L.S.). We thank Sophie Klusen for help with data acquisition.

The authors declare no competing financial interests. sity (Patel and Hu, 2008). For example, short sleep duration correlated positively with body mass index (BMI) (Shigeta et al., 2001; Heslop et al., 2002; Cournot et al., 2004) and nocturnal sleep duration correlated negatively with body fat percentage (Rontoyanni et al., 2007). In addition to endocrine mechanisms,

J.S. Rihm's present affiliation: Department of Psychology, Biological Psychology, University of Cologne, Cologne 50969, Germany.

Correspondence should be addressed to Julia Rihm at jrihm@uni-koeln.de.

https://doi.org/10.1523/JNEUROSCI.0250-18.2018

Copyright $\odot 2019$ the authors $\quad 0270-6474 / 19 / 390888-12 \$ 15.00 / 0$ 
decision-related mechanisms likely contribute to the regulation of food intake (D'Agostino and Small, 2012; Rangel, 2013) and both may consequently affect overeating following sleep loss (Chaput and St-Onge, 2014; Cedernaes et al., 2015).

The disbalance that sleep loss exerts on homeostasis can be manifested in altered levels of hormones involved in hunger and satiety. Two such candidate hormones are the orexigenic hormone ghrelin and the anorexic hormone leptin. Receptors for ghrelin (Howard et al., 1996) and leptin (Schwartz et al., 1996) are expressed in the hypothalamus, which is involved in the regulation of hunger (Anand and Brobeck, 1951) and circadian rhythm (Economo, 1930). For brain activation in response to food stimuli, ghrelin has been found to act as modulator in reward-processing areas (Malik et al., 2008; Kroemer et al., 2013; Goldstone et al., 2014). When also taking sleep loss into account, previous studies found elevated ghrelin concentrations, whereas leptin levels were decreased after sleep restriction (Spiegel et al., 2004; Taheri et al., 2004; Schmid et al., 2008; Morselli et al., 2010). For example, compared with a $7 \mathrm{~h}$ sleep period, total ghrelin levels and subjective hunger were significantly increased after restricting sleep to $4.5 \mathrm{~h}$ and even more after a night of total sleep deprivation (Schmid et al., 2008). However, studies focusing on hormonal changes as a mechanistic account of increased food intake after sleep loss often use controlled, artificial laboratory environments with little resemblance to realistic life situations (Spiegel et al., 2004; Schmid et al., 2008). Thus, endocrine modulation has recently been questioned as a major contributor to changes in food choice and the consideration of increased hedonic values of food after sleep deprivation was suggested as a possible explanation for overeating after sleep loss (Chaput and St-Onge, 2014). Therefore, control for both endocrine and hedonic aspects seems crucial in this context. At the same time, highly controlled experimental setups might not yield ecologically valid insights.

fMRI studies revealed increased neural responses to food images in regions involved in reward and motivation following total or partial sleep deprivation, such as the anterior cingulate cortex, amygdala, insula, orbitofrontal cortex, nucleus accumbens, and putamen (Benedict et al., 2012; St-Onge et al., 2012; Greer et al., 2013). However, these studies did not examine more general changes in reward processing, for example, by comparing food with nonfood control rewards or subjective reward valuation via parametric contrasts. Finally, effects on reward processing might in part be driven by sleep-deprivation-induced hormonal changes (Spiegel et al., 2004; Chaput and St-Onge, 2014). However, previous imaging studies lacked control for neuroendocrine factors.

Here, we specifically address these issues by combining approaches from decision neuroscience and endocrinology. We recorded fMRI during a neuroeconomic decision-making task (Becker et al., 1964; Chib et al., 2009) assessing subjective values of food and nonfood stimuli in a counterbalanced repeatedmeasures design after habitual sleep and a single night of total sleep deprivation. This enabled us to investigate food valuation and sleep deprivation on an intraindividual level, controlling for unspecific behavioral and fMRI effects by comparing food and nonfood rewards in each condition. Additionally, circulating hormones were assessed via blood samples obtained before fMRI scanning. We hypothesized that a full night of sleep deprivation selectively increases subjective valuation of food versus nonfood rewards, paralleled by selective increases in BOLD signals in reward- and homeostasis-related brain structures. Furthermore, we predicted elevated ghrelin concentrations after sleep depriva- tion versus habitual sleep as well as a modulation of behavior and brain activity in response to food stimuli by changes in circulating ghrelin.

\section{Materials and Methods}

\section{Participants}

Thirty-two healthy, lean, male participants (mean \pm SD age: $26.13 \pm$ 3.80 years, range: $19-33$ years; BMI: $23.32 \pm 1.44 \mathrm{~kg} / \mathrm{m}^{2}$, range: $20.52-$ $25.66 \mathrm{~kg} / \mathrm{m}^{2}$ ) participated in two fMRI sessions in counterbalanced order following a single night of sleep deprivation or habitual sleep. No blood samples could be collected from two participants and the plasma sample of one participant was not frozen immediately after centrifuging in one session, so endocrine data are only reported for 29 participants. All participants were right-handed nonsmokers who had normal or correctedto-normal vision and no history of neurological or psychiatric disorders. On average, they were good sleepers during the last 4 weeks as assed with the Pittsburgh Sleep Quality Index (Buysse et al., 1989) (PSQI Score: $4.43 \pm 0.36)$. The BMI exclusion criterion was a BMI of $25 \mathrm{~kg} / \mathrm{m}^{2}$ or higher. However, if men interested in participating in the study failed this BMI criterion during screening but had at the same time $<20 \%$ body fat, we included them in our study. This was the case for two participants (BMI: 25.66 and $25.23 \mathrm{~kg} / \mathrm{m}^{2}$; percentage body fat: $15.3 \%$ and $18.4 \%$, respectively). Participants were not on a special diet and did not have any food allergies. All experimental procedures were approved by the local ethics committee (Hamburg Board of Physicians) and all experimental appointments took place at the Institute for Systems Neuroscience at the University Hospital Hamburg-Eppendorf in Hamburg, Germany.

\section{Experimental design}

Participants visited the institute for three appointments, further described below: one screening and two counterbalanced experimental fMRI sessions with either a habitual sleep or a sleep deprivation condition separated by 1 week. The evening before the fMRI scan, they received a standardized dinner at the institute, after which they went home to sleep as usual (habitual sleep session) or stayed at the institute to spend the whole night awake under constant supervision (sleep deprivation session).

Pre-experimental screening session. After recruitment by online advertisements and a short phone interview, participants were invited to the institute $1-5 \mathrm{~d}$ before the first experimental session for a preexperimental screening. During this appointment, participants read the study description carefully and had the opportunity to ask questions concerning the procedure before giving written informed consent. We measured height, weight, body fat percentage, and the familiarity of the stimuli used in the fMRI experiment. We determined body fat percentage via the bioelectric impedance method with a BF306 device (OMRON). Furthermore, a physician conducted a short medical examination to ensure fMRI compatibility. At the end of the screening, we did not reveal the order of the two experimental sessions. Additionally, to prevent participants from sleeping during the afternoon before the sleep deprivation session when habitual sleep was the first condition, we instructed them that all combinations of the two conditions could be possible, including two habitual sleep or two sleep deprivation sessions. Therefore, participants did not know if they were to stay awake or could go home to sleep until they came in for the evening appointment. After the completion of all three sessions, we gave full disclosure of the experimental procedure.

Experimental sessions. Both experimental sessions started at 8:00 P.M. with groups of two or three participants undergoing the same experimental condition. Upon arrival, they were told the experimental condition of the night and received a standardized dinner with $741 \mathrm{kcal}$ per serving (pasta with veal strips in cream and mushroom sauce: $582 \mathrm{kcal}$ total, per $100 \mathrm{~g}$ serving: $142 \mathrm{kcal}$, fat: $6.5 \mathrm{~g}$, carbohydrate: $13.2 \mathrm{~g}$, protein $7.7 \mathrm{~g}$; apple: $68 \mathrm{kcal}$ total, per $100 \mathrm{~g}$ serving: $52 \mathrm{kcal}$, fat: $0.2 \mathrm{~g}$, carbohydrate: $14.0 \mathrm{~g}$, protein: $0.3 \mathrm{~g}$; strawberry yogurt: $91 \mathrm{kcal}$ total, per $100 \mathrm{~g}$ serving: $91 \mathrm{kcal}$, fat: $3.0 \mathrm{~g}$, carbohydrate: $13.0 \mathrm{~g}$, protein: $2.9 \mathrm{~g}$ ). Importantly, participants fasted overnight in both conditions because we instructed them to refrain from food and caloric beverages until the appointment in the morning. 
In the habitual sleep condition, participants wore an Actiwatch 2 (Philips Respironics) to track their sleep and wake times until the next morning (average sleep duration: $6.73 \pm 0.93 \mathrm{~h}$ ). They were instructed to sleep as they normally do during a typical work week, went home to spend the night as usual, and were invited again for the fMRI session the next morning between 7:30 A.M. and 9:30 A.M. In the sleep deprivation condition, participants stayed at the institute under constant supervision and spent the whole night awake. During this time, they played card games, parlor games, games on game consoles, watched television and movies, and took walks at the university area.

Each experimental session in the morning started with hunger and appetite ratings on a 7-point Likert scale, followed by Becker-deGrootMarschak (BDM) pre-scan bidding (see "BDM auction task" section), blood drawing immediately before scanning, the BDM choice phase in the scanner, and the BDM auction after scanning. We monitored participants in the scanner by online eye tracking to ensure wakefulness during the fMRI task.

\section{BDM auction task}

Participants performed a BDM (Becker et al., 1964) auction to assess their willingness to pay (WTP, i.e., subjective value) for a range of snack foods (food reward) and trinkets (nonfood reward) (Plassmann et al., 2007; Chib et al., 2009). In this task, participants had the opportunity to win a trinket and a snack item (factor reward category with levels "food" and "nonfood"). The task consisted of three phases, reported below in more detail: (1) a prescan free bidding phase to obtain subjective value estimates for all items, (2) a decision phase in the scanner, and (3) a postscan auction phase. The procedure for the BDM auction closely followed previous studies (Plassmann et al., 2007; Chib et al., 2009). In particular, care was taken to ensure that all participants understood the auction procedure and that the best strategy was to bid exactly the maximum amount that they were willing to pay for an item in the prescan phase. Also, participants were instructed that, following scanning on each day, one trial per item category (food and nonfood) from the combined set of trials from the bidding and decision phase would be selected and played out. All snacks and trinkets were available and arranged in the testing room such that all choices involved the prospect of obtaining the actual rewards.

Prescan bidding phase. In the bidding phase (Fig. 1a), participants received $3 €$ to spend on snacks and $3 €$ to spend on trinkets. They saw all food and nonfood images and indicated their WTP for each item on a scale from $0 €$ to $3 €$ in steps of $0.25 €$. They were instructed to bid the maximal amount that they were willing to spend on the item and that they could use the full range of the $3 €$ for each item because only one item per category was drawn in the auction at the end. After bidding on all items, the median of all food and nonfood items bid values was calculated separately for each participant and session and used as reference price in the respective fMRI decision phase (Chib et al., 2009). We informed participants about the reference price and carefully ensured that they correctly understood it by checking repeatedly if they remembered and could reproduce the correct reference price. Additionally, the reference price was displayed on the task screen while positioning the participants in the scanner as well as during the first minutes during positioning. Before the fMRI task started, we briefly instructed the participants again over an intercom with the choice task and the reference price.

fMRI decision phase. During the choice phase in the fMRI scanner, participants underwent a task in which they made repeated choices between buying or rejecting an item for the median price over all items (Fig. 1b). Participants saw all snack and trinket images again and had to indicate if they would buy or reject them for the reference price, which was the median bid over all food and nonfood items and was calculated for each participant and session. In a typical trial, participants saw a green dot for $0.5 \mathrm{~s}$, followed by the food or nonfood item for $6 \mathrm{~s}$. Subsequently, a red cross (reject) and a green check mark (accept) appeared randomly left and right of the image for $2 \mathrm{~s}$, indicating the decision-making phase. Participants made choices via a MRI-compatible button box. The intertrial interval was marked by a red dot with a randomized presentation time between 2 and $6 \mathrm{~s}$ sampled from a uniform distribution.

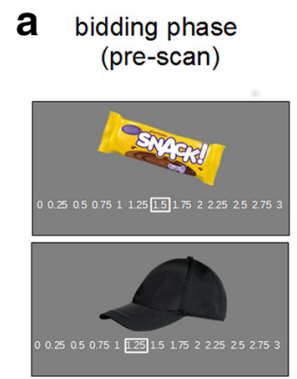

b decision phase

(during fMRI)

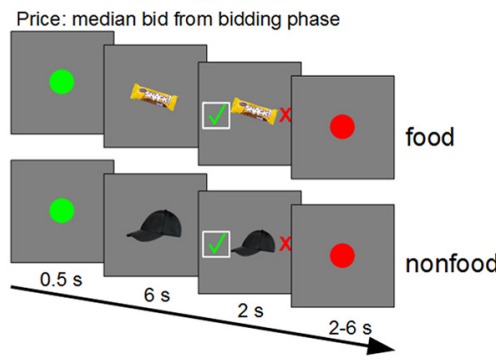

Figure 1. Outline of the BDM task structure of the prescan bidding phase (a) and the fMRI decision phase $(\boldsymbol{b})$.

Postscan auction. In the auction after scanning, one trial per category was randomly drawn from all trials of the bidding and choice phases. For trials of the bidding phase, the participants' auction bid was the bidding value, whereas for trials of the choice phase, the participants' auction bid was the reference price in case the participants accepted the item or $0 €$ in case they rejected it. The participants' bid competed against a randomly generated price by the computer between $0 €$ and $3 €$ in $0.25 €$ steps. If the participants' price was higher than or equal to that of the computer, then they purchased the snack for the lower price and additionally received the difference amount to $3 €$. If the computer-generated price was higher than the participants' price, then the item could not be bought but participants received the full $3 €$. After the auction, participants stayed another $30 \mathrm{~min}$ at the institute and could not eat anything except the snack if they had purchased one.

\section{Stimuli}

Visual stimuli consisted of 48 different snack food and 48 different trinket images. The presented snacks were familiar snack foods available in Germany [mean \pm SD familiarity: $3.88 \pm 0.66$, scale from 1 (not familiar) to 5 (highly familiar)] such as chocolate bars and chips as compiled from an internet search and a previous study (Gluth et al., 2015). Trinkets were familiar [mean \pm SD familiarity: $3.64 \pm 0.75$, scale from 1 (not familiar) to 5 (highly familiar)] everyday items such as office, drugstore, or university merchandise items compiled from an internet search and inspired by the trinket items used in Chib et al. (2009).

All images were resized to 400 pixels in the largest dimension, superimposed on a gray background image, and presented with Presentation software version 18 (Neurobehavioral Systems; RRID:SCR_002521). For each participant, half of the 48 stimuli from each category were randomly chosen and presented on the first scanning day, the other half on the second scanning day. Because we did not take into account caloric density of the snack food items for randomization, we conducted a post hoc analysis to confirm that the randomized stimuli sets of the habitual sleep and sleep deprivation sessions were matched according to caloric density by analyzing relatively high and relatively low caloric density between sessions. For this purpose, we median split the snack food stimulus set based on caloric content per $100 \mathrm{~g}(\mathrm{kcal} / 100 \mathrm{~g})$ into relatively high and relatively low caloric items. A repeated-measures ANOVA with the factors sleep state (habitual sleep vs sleep deprivation) and caloric density (relatively higher vs lower caloric density) revealed no main effect of sleep state $\left(F_{(1,31)}=0.24, p=0.63\right)$ and no interaction between the two factors $\left(F_{(1,31)}=0.08, p=0.78\right)$. However, there was a significant difference between the caloric content of the relatively high and low caloric density items $\left(F_{(1,31)}=75337.05, p<0.001\right.$; mean $\mathrm{kcal} / 100 \mathrm{~g}$ for low caloric density: habitual sleep: $404.72 \pm 1.66$, sleep deprivation: $406.39 \pm 1.67$; for high caloric density: habitual sleep: $546.79 \pm 1.31$, sleep deprivation: $547.71 \pm 1.25)$.

Images from both categories were mixed and randomly presented in two runs per session. In the scanner, images were projected on a wall and participants saw them via a mirror mounted on the head coil.

\section{Blood sampling and analyses}

We took blood plasma and serum samples in both sessions to determine circulating levels of ghrelin, leptin, insulin, cortisol, and glucose. Collec- 
tion of blood samples took place immediately before fMRI scanning to measure endocrine concentrations during the fMRI BDM choice task.

Plasma blood samples of $8.5 \mathrm{ml}$ were collected in BD P800 tubes (BD Biosciences) containing $\mathrm{K}_{2}$ EDTA anticoagulant for ghrelin concentration determination. They were immediately preprocessed by centrifuging at $4^{\circ} \mathrm{C}$ for $10 \mathrm{~min}$ at $1200 \times \mathrm{g}$, pipetting off the supernatant, and stored at $-80^{\circ} \mathrm{C}$.

Serum blood samples of $7.5 \mathrm{ml}$ were collected in Serum Gel Monovettes (Sarstedt) to determine leptin, cortisol, and insulin concentrations. The blood soaked for $45 \mathrm{~min}$ in the gel solution before the samples were centrifuged at room temperature for $10 \mathrm{~min}$ at $2000 \times \mathrm{g}$. The supernatant was pipetted off and stored at $-80^{\circ} \mathrm{C}$.

Two additional serum samples of $2.7 \mathrm{ml}$ each for glucose determination were collected in Sarstedt S-Monovettes with Fluorid EDTA and also soaked for $45 \mathrm{~min}$ in gel solution before centrifuging at room temperature for $10 \mathrm{~min}$ at $2000 \times \mathrm{g}$. The supernatant was pipetted off and stored at $-80^{\circ} \mathrm{C}$.

All serum blood samples were analyzed by the LADR laboratory in Geesthacht, Germany. Leptin was analyzed with a sandwich enzymelinked immunosorbent assay (ELISA) from DRG, cortisol and insulin with an electro-chemiluminescence immunoassay (ECLIA) method from Roche, and glucose with a photometric AU 5800 from Beckman Coulter.

Total and acyl ghrelin concentrations were analyzed at the Metabolic Core Unit, CBBM, in Luebeck, Germany with a radioimmune assay (Millipore).

\section{fMRI data acquisition}

fMRI data were obtained on a Siemens Magnetom Trio 3 T whole-body scanner using a 32-channel head coil. Functional images were collected using single-shot echoplanar imaging with parallel imaging (GRAPPA, in-plane acceleration factor 2) (Griswold et al., 2002) and simultaneous multi-slice acquisitions ("multiband," slice acceleration factor 2) (Feinberg et al., 2010; Moeller et al., 2010; Xu et al., 2013) as described previously (Setsompop et al., 2012) ( TR $=2260 \mathrm{~ms}, \mathrm{TE}=30 \mathrm{~ms}$, number of slices $=60$, flip angle $=80^{\circ}$, voxel size $\left.=1.5 * 1.5 * 1.5 \mathrm{~mm}\right)$. The corresponding image reconstruction algorithm was provided by the University of Minnesota Center for Magnetic Resonance Research.

\section{Statistical analysis for behavioral data}

Paired-samples $t$ tests with a significance threshold of $p<0.05$, twotailed, were computed using MATLAB R2016b (RRID:SCR_001622) and repeated-measures ANOVAs were computed using JASP 0.8.1.2 (RRID: SCR_015823).

Hunger ratings. Subjective hunger ratings before the BDM task were compared between sessions with a paired-samples $t$ test.

Bids and reaction times. We assessed differences between bids and reaction times from the BDM prescan bidding phase using $2 \times 2$ repeatedmeasures ANOVAs with the factors sleep state (habitual sleep, sleep deprivation) and reward category (food, nonfood).

As suggested by one reviewer, we conducted a post hoc analysis to examine the impact of caloric density (kcal per $100 \mathrm{~g}$ ) of the snack food items on WTP for these items. For this purpose, we median split food datasets of each participant and each session into relatively high and relatively low caloric items and computed a repeated-measures ANOVA with the factors sleep state (habitual sleep, sleep deprivation) and caloric density (relatively low caloric density, relatively high caloric density).

As another post hoc analysis requested by one reviewer, we additionally correlated the change in subjective value of the items reflected by the change in the difference between bids for food and bids for nonfood items between the two states with the change between the two states for food and nonfood items in all behavioral (change in hunger, change in reaction times, and change in probability to buy items for the reference price) and neural parameters (change in $\beta$ values for parametric WTP modulation in the and right hypothalamus, change in $\beta$ values related to image onsets in the amygdala, and change in $\beta$ values for PPI image onset-related activity for the connectivity between amygdala and hypothalamus) as exploratory analysis. Due to multiple correlations, we applied a Bonferroni correction for multiple comparisons $(p=0.05 / 7)$.
Percentage irrational choices. Irrational choices are choices during the choice phase that are not predicted based on the subjective values from the bidding phase. Irrational choices were thus defined as rejections when the reference price was equal to or smaller than the subjective value assessed during bidding or as acceptance when the reference price was higher than the subjective value assessed during bidding. The number of irrational choices was divided by the total number of decision trials and multiplied by 100 .

Probability to buy. The probability to buy an item $[\mathrm{p}($ buy $)]$ for the individual median bid during the scanning choice phase was calculated by dividing the number of accepted by the total number of items. Differences between sleep states and reward categories were compared with a repeated-measures ANOVA.

Hierarchical Bayesian drift diffusion modeling (DDM). To further supplement analyses of bidding behavior, individual participant's choice and reaction time data were fit with a DDM (Ratcliff and McKoon, 2008). During the scanning choice phase, participants made repeated choices between the presented reward (trinket or snack) and the prescanning median bid from the BDM auction. The DDM is a frequently used model describing two-alternative forced-choice tasks and has been shown to be valid in the context of value-based choices (Milosavljevic et al., 2010). The choice process is modeled as a noisy evidence accumulation process over time between two boundaries. As soon as one of the boundaries is crossed, the associated response is executed. This evidence accumulation is described by several underlying parameters, which in turn give rise to the reaction time distributions for correct and incorrect choices (Ratcliff and McKoon, 2008). The drift rate $v$ reflects the rate of evidence accumulation over time; the boundary separation $a$ reflects the amount of evidence required to execute a choice; the nondecision time parameter $t$ captures the time needed to perceive the stimulus and execute a motor response; and $z$ corresponds to the starting point of the evidence accumulation process between the two boundaries and was fixed at the midpoint between the two boundaries in the model. In addition, intertrial variability in nondecision time $(S t)$ was included in the model because setting it to zero might be problematic for model estimation (Voss et al., 2015). Correct choices were defined as choices consistent with the median bid from the prescan bidding phase; that is, buying the item if the bid was greater than or equal to the median bid and rejection if the bid was less than median bid, whereas incorrect choices were defined as choices inconsistent with the median bid from the prescan bidding phase.

Parameter values were estimated using a hierarchical Bayesian parameter estimation procedure based on Markov Chain Monte Carlo simulation via a Python-based toolbox, the hierarchical DDM (HDDM) (Wiecki et al., 2013). There are two key advantages to this method. First, hierarchical models estimate group and individual parameters simultaneously, allowing the group estimates to constrain the values of individual parameter estimates. Therefore, fewer trials are needed to reliably estimate individual parameter values. Second, the posterior distributions derived by Bayesian estimation procedures provide the most likely parameter estimates as well as a measure of uncertainty in these estimates.

Two independent but equivalent models were estimated for the habitual sleep and the sleep deprivation conditions. For both models, 20,000 samples were drawn from the posterior distribution. Two thousand of these samples were discarded as burn-in. Successful chain convergence was assessed by comparing interchain and between-chain variance with the Gelman-Rubin statistic (Gelman et al., 2013). It was hypothesized that an increase in standardized absolute value difference between the median bid from the bidding phase and the presented stimulus in the choice phase of the task would influence the drift rate differently for the habitual sleep compared with the sleep deprivation condition. Similar to previous studies that have examined conflict-dependent changes in drift rates associated with sleep deprivation (Menz et al., 2012), we expected that sleep-deprived participants would show a diminished effect of standardized absolute value difference on the drift rate and thus attenuated conflict-dependent slowing. Therefore, drift rates were modeled using a regression approach as a linear function of the standardized absolute value difference in each of the compared models. The linear model used to estimate the trial-by-trial drift rate contained one intercept and a slope parameter for each of the two stimulus types (food vs nonfood rewards). 
This HDDM regression approach has been described previously (Wiecki et al., 2013) and has been applied in a number of previous studies (Cavanagh et al., 2011; Herz et al., 2016).

\section{Statistical analysis for endocrine data}

All analyses with endocrine data were conducted using MATLAB R2016b. For visualization, raw values of endocrine data were compared using nonparametric Wilcoxon signed-rank tests with a two-tailed significance threshold of $p<0.05$, as shown in Table 5 and Figure 7, but due to skewed distributions, we log-transformed all endocrine parameters before further analyses.

In an exploratory analysis, we additionally calculated the homeostatic model assessment for insulin resistance (HOMA-IR) as a measure for insulin sensitivity with the following equation (Matthews et al., 1985): insulin $\left(\mathrm{mU1}^{-1}\right)^{\star} \operatorname{glucose}\left(\mathrm{mmol} \mathrm{1} 1^{-1}\right)$.

\section{5}

We calculated correlations between log-transformed ghrelin and leptin parameters and the interaction between sleep state and category of the extracted $\beta$ values of the valuation signals in left and right hypothalamus, the image-onset-related activity in left and right amygdala, and the coupling between right amygdala and left hypothalamus.

Furthermore, we also calculated multiple linear regression models with changes in all hormone parameters between sessions as predictors and the extracted $\beta$ values of the fMRI interaction contrasts of interest as criteria. A correlational analysis between the changes in hormone concentrations from habitual sleep to sleep deprivation sessions revealed a strong correlation between des-acyl ghrelin and total and acyl ghrelin and between leptin and insulin. We only included the four noncorrelated predictors in the multiple linear regression models: des-acyl ghrelin, leptin, glucose, and cortisol. As criteria, we used the interaction between sleep state and category of the extracted $\beta$ values of the valuation signals in right hypothalamus, the image-onset-related activity in right amygdala, and the coupling between right amygdala and left hypothalamus.

We calculated des-acyl ghrelin concentrations by subtracting raw values of acyl from total ghrelin values.

\section{Statistical analysis for $f M R I$ data}

Preprocessing and noise regressors. Imaging data were analyzed using SPM12 (http://www.fil.ion.ucl.ac.uk/spm/; RRID:SCR_007037). After removing the first five scans, images were realigned to the first scan and unwarped to account for movement-related effects. The anatomical image scan was then coregistered to the mean realigned EPI image and segmented into gray matter, white matter, and CSF. For each subject and session, we additionally computed noise regressors in two steps. First, we created a combined white matter and CSF mask image. Second, we calculated a principal component analysis over all voxels in the mask, identifying all principal components that explained $>1 \%$ of the variance in the mask time series. These principal component scores were included in the first-level models as regressors of no interest (mean \pm SEM number of components: sleep deprivation $8.75 \pm 0.3$; habitual sleep $7.69 \pm 0.28$ ).

First-level analyses. After preprocessing, we set up a general linear model at first level in single-subject space. For each session, we included the following regressors, which were convolved with the hemodynamic response function: (1) onsets of the snack food images as stick function; (2) WTP values on these food items, that is, subjective values, as first parametric modulator; (3) squared bid values on these food items as second parametric modulator; (4) onsets of the nonfood trinket images as stick function; (5) WTP values on these nonfood items, that is, subjective values, as first parametric modulator; (6) squared bid values on these nonfood items as second parametric modulator; (7) regressor of no interest coding for error trials; and (8) noise regressors (see above) as additional nonconvolved covariates. Normalization parameters were obtained for the structural scans and applied to the single-subject contrast images, writing the normalized contrasts with $1.5 * 1.5 * 1.5 \mathrm{~mm}$. Normalized contrast images were smoothed with a $6 \mathrm{~mm}$ full-width at halfmaximum isotropic Gaussian kernel.

Second-level models. Sleep-state-dependent changes in BOLD activation related to stimulus onsets and valuation signals (parametric effects of WTP) were analyzed on the second level via a flexible factorial model with the within-subject factors reward category (food, nonfood) and sleep state (sleep deprivation, habitual sleep).

Psychophysiological interaction analysis (PPI). We also investigated sleep state $\times$ reward-category-dependent changes in functional connectivity via PPIs (Friston et al., 1997). For the PPI analysis, we had to bring single-subject data into MNI space and therefore reran preprocessing as described above with the addition of normalizing the EPIs to MNI space, writing them with $1.5^{\star} 1.5{ }^{\star} 1.5$ voxel and smoothing the images with a $6 \mathrm{~mm}$ full-width at half-maximum isotropic Gaussian kernel. These preprocessed images were the basis for the PPI analysis described below. Because this is a different preprocessing pipeline than in our original model, we also computed first-level models and a flexible factorial second level as described above with these MNI-preprocessed images as a sanity check for peaks of the BOLD activation related to stimulus onset and for valuation signals. The peaks are crucial because they are used as seeds for the PPI analyses. These seed regions were determined by peaks in ROIs that reached a familywise error (FWE)-small volume correction (SVC)-corrected $p$-value $<0.05$ in the flexible factorial contrasts for BOLD activation related to stimulus onset and for valuation signals. Comparisons between the peak coordinates of the MNI-preprocessed second-level models and the single-subject space-preprocessed models revealed highly similar localization: As in the original analysis, the right amygdala [MNI coordinates $(x, y, z)=(21,-4,-25)]$ revealed higher activation for snack onset compared with trinket onset images after sleep deprivation compared with sleep, whereas the right hypothalamus clusters $(4,-1,-10)$ and left $(-4,-6,-12)$ showed sleep state $\times$ reward category interaction effects with respect to valuation signals.

For the PPI analysis, we proceeded as follows for each subject and each session: We extracted time series in the peak voxels from preprocessed images, created PPI regressors for BOLD activation related to food stimuli onsets and food valuation signals $<$ BOLD activation related to nonfood stimuli onsets and nonfood valuation signals, and calculated an additional PPI first level model with the user-defined PPI regressors and noise regressors. We then compared BOLD activation related to stimulus onset and valuation signals between sleep deprivation and habitual sleep groups with a second-level paired $t$ test model.

Correction for multiple comparisons. All results are reported using FWE-corrected $p$-values based on anatomical or function regions of interest (ROIs). We focused on three different ROIs and conducted FWESVC with all of these three ROIs in each contrast. First, we were interested in reward-related regions, in particular vmPFC, ventral striatum, and posterior cingulate. Previous studies using the BDM auction task focused on the vmPFC (Plassmann et al., 2007; Chib et al., 2009). For assessing brain activation in the reward system including vmPFC, we used a twostep SVC procedure. First, we used a reward ROI mask provided by the Rangel Neuroeconomics Laboratory (www.rnl.caltech.edu/resources/ index.html) encompassing regions involved in reward processing and valuation. This mask is a conjunction of the results of two published meta-analyses (Bartra et al., 2013; Clithero and Rangel, 2014) defining areas that positively correlate with reward value and it has the advantage that it encompasses a bilateral value-associated vmPFC mask and additional reward-related regions such as bilateral ventral striatum, posterior cingulate cortex (PCC), and anterior cingulate (ACC). In a second step, we confirmed the precise anatomical localization of clusters surviving SVC within the reward mask via a $5 \mathrm{~mm}$ sphere around peak coordinates of Chib et al. (2009) $(-9 / 39 /-6)$ for vmPFC and peak coordinates of Suzuki et al. (2017) $(-36 / 26 /-11)$ for lateral OFC. Second, we focused on the hypothalamus as one of the most important regions in food and circadian regulation (Economo, 1930; Anand and Brobeck, 1951) and created a bilateral hypothalamus mask using an automated neurosynth meta-analysis with the keyword "hypothalamus" (www.neurosynth.org; RRID:SCR_006798). We thresholded the resulting reverse inference map at $z \geq 18$ to exclude unspecific activation and saved it as binary mask image. Note that this approach is not directly based on anatomical considerations, but rather depends on how researchers commonly classify imaging activations as being located in the hypothalamus. We checked that the choice of hypothalamus ROI did not affect the primary hypothalamus interaction effect. That is, in the right hypothalamus, the sleep 

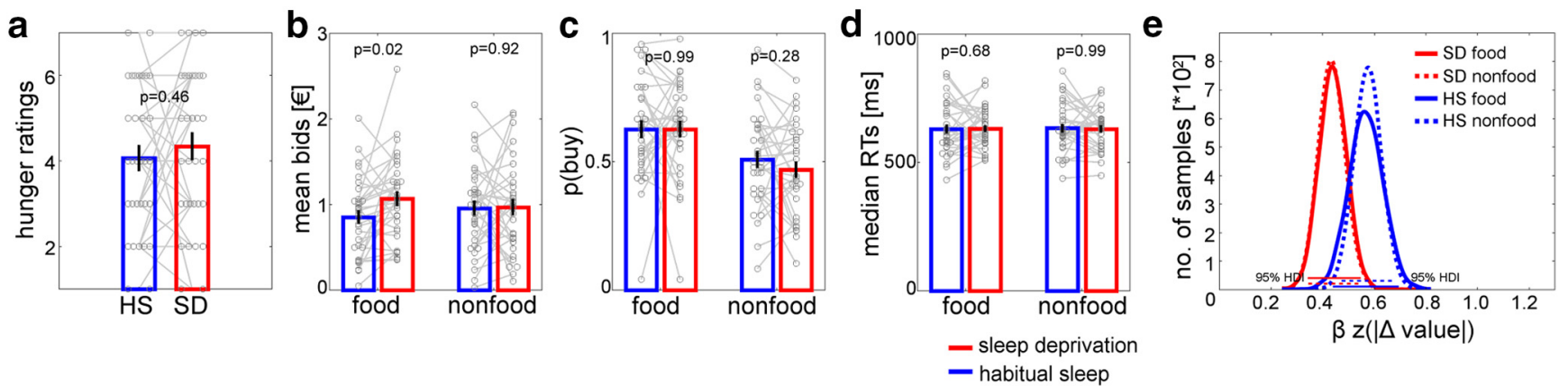

Figure 2. Behavioral data. Subjective hunger ratings (a) did not differ significantly between habitual sleep ("HS"; blue) and sleep deprivation ("SD”; red). After sleep deprivation, WTP specifically increased for food compared with nonfood $(\boldsymbol{b}$, sleep state $\times$ reward category interaction, $p=0.03)$. The probability to buy snacks for the reference price during scanning only showed a main effect of category $(\boldsymbol{c}, p<0.001)$ and reaction times did not differ significantly across sleep and category ( $\boldsymbol{d}$, all $p>0.58)$. Diffusion modeling suggested attenuated conflict-induced reductions in drift rate following sleep deprivation for both food and nonfood rewards (e). Data are shown as mean \pm SEM.
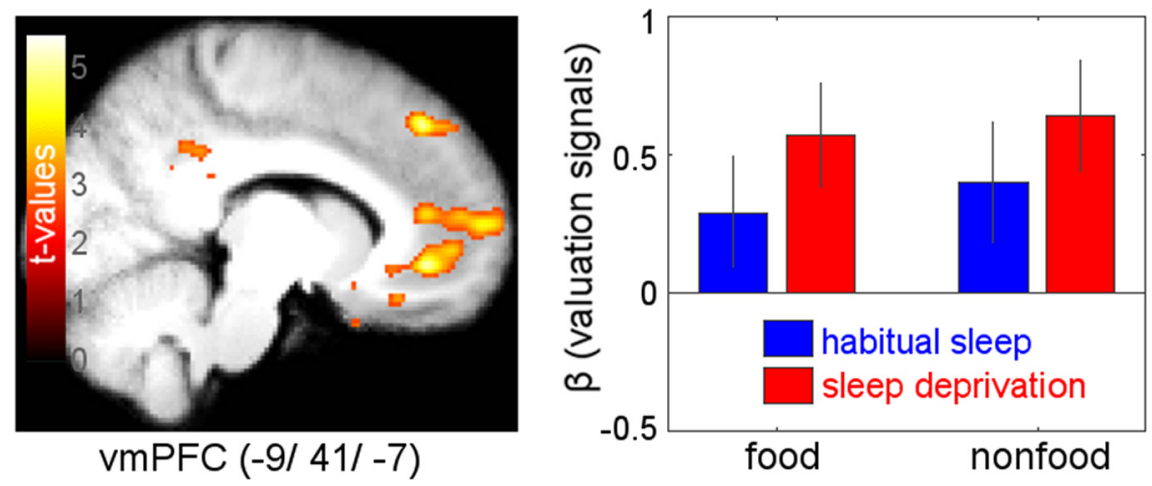

Figure 3. Main effect of parametric valuation signals (WTP) across both reward categories (food, nonfood) and both states (habitual sleep, sleep deprivation). Effects are revealed in $\operatorname{vmPFC}(-9,41,-7): z=4.78, p=0.001$, FWE-SVC-corrected; display threshold: $p<0.005$, uncorrected.

state $\times$ reward category interaction effect also survived correction across a bilateral anatomical hypothalamus from the WFU Pick Atlas (Maldjian et al., 2003, 2004; RRID:SCR_007378) [(4, $-2,-10): z=2.91, p=0.024$, FWE-SVC-corrected] and when coordinate-based ROIs were used as in a previous study (Kullmann et al., 2015) (medial hypothalamus (4, -2, -12) $+2 \mathrm{~mm}$ sphere radius; $z=2.91, p=0.008$, FWE-SVC-corrected). As a third ROI, we focused on the amygdala because it was revealed as region of activation in the context of homeostasis-related processing (Sun et al., 2015) and after a food-related value-based decision making task after sleep deprivation (Greer et al., 2013). A bilateral amygdala mask was taken from the WFU Pick Atlas by combining the provided masks for the left and right basolateral amygdalae (Maldjian et al., 2003, 2004).

For display purposes, activation in fMRI figures is thresholded at $p<$ 0.005 , uncorrected. Activations are projected on a skull-stripped mean anatomical image created with the SPM function "imcalc." Individual skull-stripped images were created for each participant by using only those voxels of the individual anatomical image matching the segmented white and gray matter images and after that normalized and averaged.

\section{Results}

\section{Behavioral results}

Before scanning, subjective feelings of hunger did not differ significantly between sleep deprivation and habitual sleep (Fig. $2 a$, $\left.t_{(31)}=0.75, p=0.46\right)$. WTP as assessed in the prescan auction phase increased selectively for food rewards after sleep deprivation ( leep state $\times$ reward category interaction $F_{(1,31)}=5.48, p=$ 0.03 ; Fig. $2 b$ ). A post hoc analysis of the food bids separated by sleep state and caloric density revealed a main effect of sleep state $\left(F_{(1,31)}=5.65, p=0.02\right)$, a main effect of caloric density $\left(F_{(1,31)}=\right.$
14.97, $p<0.001)$, and a trend of an interaction between these factors $\left(F_{(1,31)}=\right.$ 4.05, $p=0.053)$.

During fMRI, participants made purchasing decisions for all items from the prescan bidding phase with the reference price set to each participant's median bid. The percentage of irrational choices was not significantly different between habitual sleep $(22.34 \pm 2.20 \%)$ and sleep deprivation $\left(23.90 \pm 1.90 \% ; t_{(31)}=-0.53, p=\right.$ $0.60)$. The $\mathrm{p}$ (buy) was higher for snacks veresus trinkets (main effect category: $F_{(1,31)}=26.54, p<0.001$; Fig. $\left.2 c\right)$, but was not differentially modulated by sleep $\left(F_{(1,31)}=0.35, p=0.56\right.$; Fig. $\left.2 c\right)$ or a sleep $\times$ category interaction $\left(F_{(1,31)}=\right.$ $0.77, p=0.39$; Fig. $2 c$ ). Note that the reference price was individually adapted for each session which explains why the state $\times$ category interaction on WTP is not reflected in $\mathrm{p}$ (buy). There were no effects of sleep state $\left(F_{(1,31)}=0.05, p=0.83\right.$; Fig. $\left.2 d\right)$ or reward category $\left(F_{(1,31)}=0.03, p=0.87\right.$; Fig. $\left.2 d\right)$ on median reaction times, nor was there an interaction $\left(F_{(1,31)}=0.6, p=0.44\right.$; Fig. $\left.2 d\right)$. We further examined choice dynamics using a hierarchical Bayesian implementation (Wiecki et al., 2013) of the DDM (Ratcliff and McKoon, 2008), modeling linear changes in the drift rate $v$ across trials $t$ as a function of $\mid W T P(t)-$ medianbid $\mid$ using a full DDM with a linear term for $v$. Descriptively, conflict-dependent slowing tended to be reduced for both reward conditions after sleep deprivation compared with habitual sleep (Fig. $2 e$, but note that the $95 \%$ highest density intervals for the regression coefficients showed some overlap).

Correlation analyses including WTP and behavioral measures revealed that the change in subjective values from food to nonfood items between sessions was not correlated with the change in hunger ratings, nor with the change in reaction times for decisions in the choice phase of the BDM task (all $R \geq-0.25$, all $p \geq$ 0.12 ). However, the change in subjective value was positively correlated with the change in the probability to buy items during the scanner choice phase $(r=0.50, p=0.004$, significant after Bonferroni correction for multiple comparisons).

\section{fMRI results}

fMRI revealed a main effect of subjective value across sleep states and reward categories in vmPFC $[\mathrm{MNI}$ coordinates $(x, y, z)=$ 


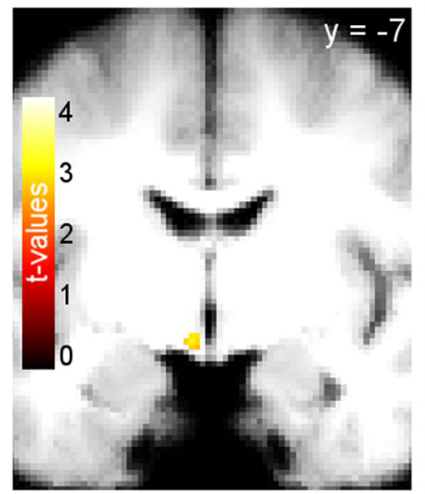

left hypothalamus $(-4 /-7 /-12)$

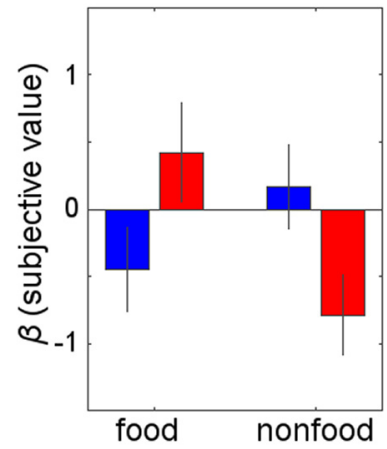

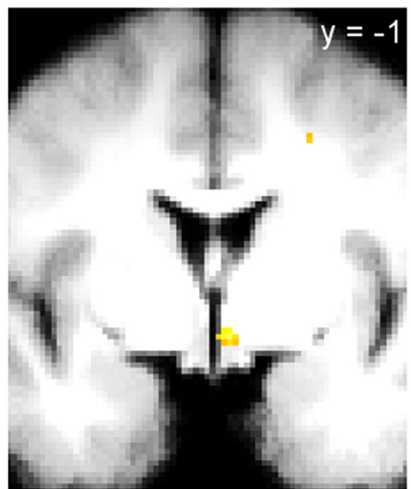

right hypothalamus $(4 /-1 /-10)$

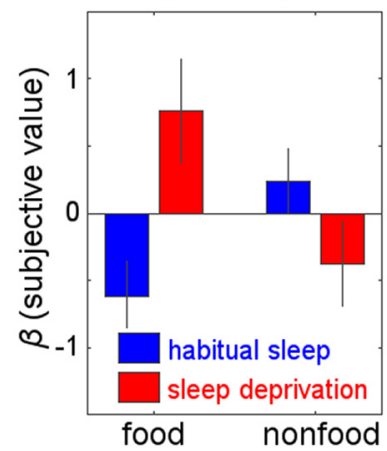

Figure 4. Parametric value effects on BOLD amplitude. Sleep state $\times$ reward category interaction contrast for valuation signals revealed food-specific valuation increases in bilateral hypothalamus following sleep deprivation [right $(4,-1,10): z=3.27, p=0.018$, FWE-SVCcorrected; left $(-4,-7,-12): z=2.92, p=0.048$, FWE-SVC-corrected; display threshold: $p<0.005$, uncorrected].

$(-9,41,-7) ; z=4.78, p=0.001$, FWE-SVC-corrected with reward ROI mask; the identical peak survives FWE-SVC $(p<$ 0.001 ) across a vmPFC ROI based on Chib et al. (2009) for confirmation of anatomical localization, see Materials and Methods; Fig. 3]. None of the other whole-brain-uncorrected clusters survived SVC across the reward ROI or the other two ROI masks. In contrast, bilateral hypothalamus and amygdala both showed distinct sleep $\times$ reward category interaction effects. Valuation signals [i.e., parametric effects of WTP on BOLD amplitude) in bilateral hypothalamus (right $(4,-1,-10): z=3.27, p=0.018$, FWE-SVC-corrected; left $(-4,-7,-12): z=2.92, p=0.048$ FWE-SVC-corrected; Fig. 4] were selectively increased for food rewards following sleep deprivation. None of the other wholebrain-uncorrected clusters survived SVC across the other two ROI masks. Additionally, BOLD activation related to stimulus onset in bilateral amygdala [right $(20,-2,-25): z=3.48, p=$ 0.04, FWE-SVC-corrected; left $(-24,-7,-25): z=3.19, p=$ 0.088, FWE-SVC-corrected; Fig. 5] was selectively enhanced for food rewards following sleep deprivation. None of the other whole-brain-uncorrected clusters survived SVC across the other two ROI masks.

We then ran PPI analyses with the three significant clusters of the onset-related and valuation interaction analyses (right amygdala, left and right hypothalamus; see Figs. 4,5 ) by using the peak coordinates as seed regions.

The PPI with the seed in the right amygdala then revealed coupling with left hypothalamus $[(-6,-7,-12): z=3.50, p=$ 0.011, FWE-SVC-corrected; with right hypothalamus $(9,-4$, $-12): z=2.67, p=0.098$, FWE-SVC-corrected; Fig. 6] and with

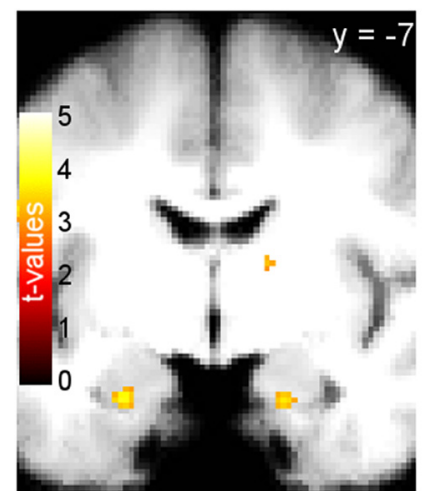

left amygdala

$(-24 /-7 /-25)$

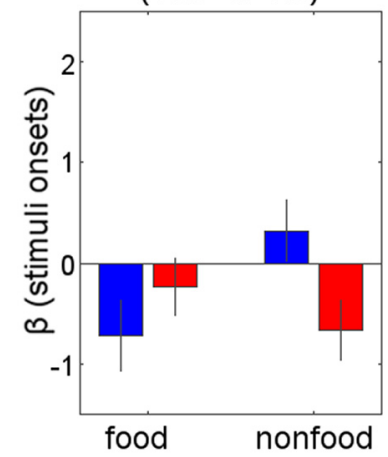

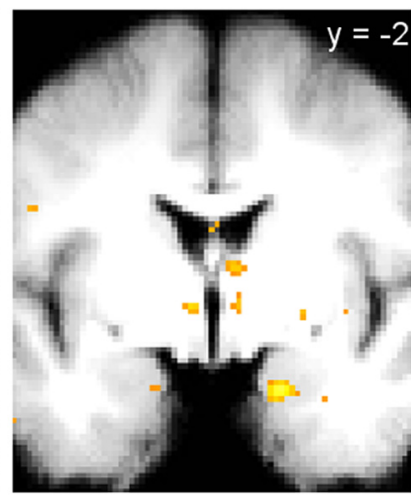

right amygdala

$(20 /-2 /-25)$

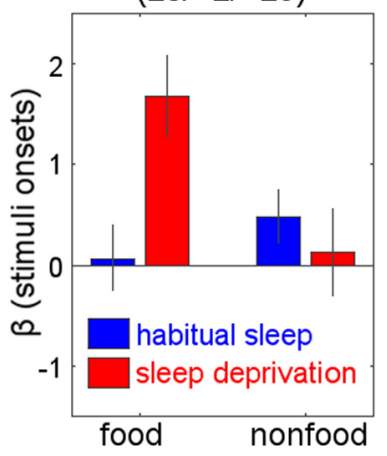

Figure 5. BOLD activation related to stimulus onset. Sleep state $\times$ reward category interaction with respect to stimulus onset revealed increased activation in bilateral basolateral amygdala for food versus nonfood rewards following sleep deprivation versus habitual sleep [right $(20,-2,-25): z=3.48, p=0.04$, FWE-SVC-corrected; left $(-24,-7,-25): z=$ $3.19, p=0.088$, FWE-SVC-corrected; display threshold: $p<0.005$, uncorrected].

left lateral OFC $[(-24,28,-16), z=4.33, p=0.008$, FWE-SVCcorrected with reward ROI mask; the identical peak survives FWE-SVC ( $p=0.005)$ across a lOFC ROI based on Suzuki et al. (2017) for confirmation of anatomical localization, see methods; for lists of all activated brain regions in each of the four above described contrasts see Tables 1, 2, 3, and 4]. Therefore, these regions also showed a food-specific increase in functional connectivity following sleep deprivation versus habitual sleep. The changes in neural activity between states and categories were not correlated with the change in subjective value reflected in the bids (all $R \leq$ 0.24 , all $p \geq 0.18$ ).

Neither left nor right hypothalamus was coupled with any of the ROIs.

\section{Endocrine results}

Blood samples collected immediately before fMRI scanning revealed that sleep deprivation induced a distinct morning increase in des-acyl ghrelin (Wilcoxon signed-rank test: $z=2.27, p=$ 0.04; Fig. 7b), whereas morning levels of total ghrelin, acyl ghrelin, leptin, insulin, glucose, cortisol, and HOMA-IR measures did not differ significantly between sleep deprivation and habitual sleep (all $p \geq 0.11$; Fig. 7a,c-g, Table 5). All hormone parameters were significantly correlated between the two conditions (all $R \geq$ 0.44 , all $p<0.02)$, with the exception of glucose $(r=0.16$, $p=0.40)$.

Based on these ghrelin differences between sessions, we conducted further exploratory analyses with the three ghrelin parameters. The magnitude of the intraindividual increases in ghrelin between sessions neither correlated with the change in WTP for 
PPI seed: amygdala

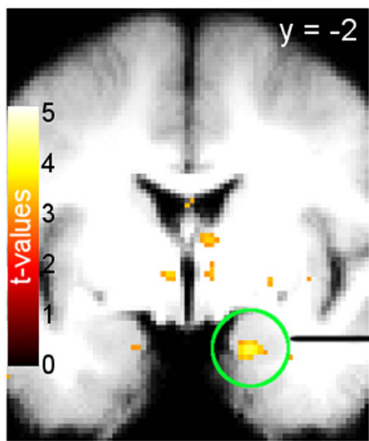

PPI food $>$ nonfood

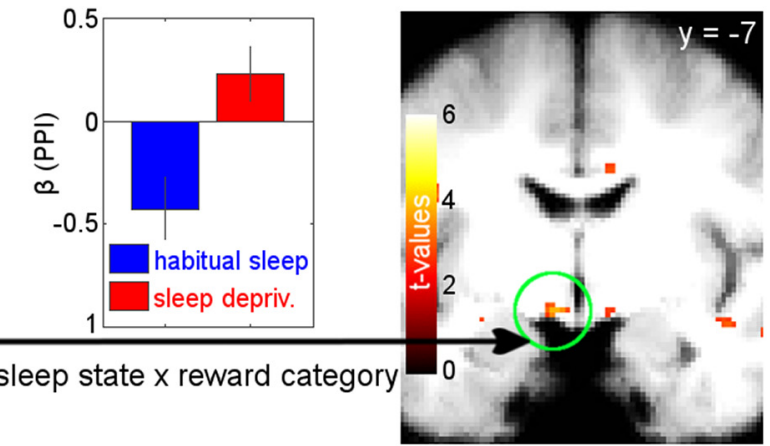

Figure 6. Functional connectivity results from PPI. The seed was placed in the right amygdala peak of the contrast for activation related to stimulus onset, showing higher activation for food versus nonfood items following sleep deprivation versus habitual sleep (left). Coupling of this seed with left hypothalamus [left $(-6,-7,-12): z=3.50, p=0.011$, FWE-SVC-corrected; right panel] was significantly greater for food versus nonfood in sleep deprivation versus habitual sleep. The center panel shows the food versus nonfood coupling parameters for sleep deprivation and habitual sleep.

Table 1. Brain regions where valuation signal activation increased for both categories (food and nonfood) and both states (sleep deprivation and habitual sleep), for $p<0.001$, uncorrected, with at least 5 contiguous voxels

\begin{tabular}{|c|c|c|c|}
\hline Region & $\begin{array}{l}\text { Cluster } \\
\text { size }\end{array}$ & MNI coordinates $(x, y, z)$ & $z$-value \\
\hline L superior frontal gyrus & 439 & -144042 & $5.18^{*}$ \\
\hline $\begin{array}{l}\text { L ventromedial prefrontal cortex/ } \\
\text { medial orbitofrontal cortex }\end{array}$ & 1381 & $-941-7$ & 4.78 \\
\hline L angular gyrus & 572 & $-50-6240$ & 4.47 \\
\hline R parahippocampal gyrus & 53 & $10-1-31$ & 4.29 \\
\hline L posterior cingulate gyrus & 52 & $-3-5020$ & 4.24 \\
\hline R inferior occipital gyrus & 119 & $44-86-8$ & 4.02 \\
\hline R inferior frontal gyrus, orbital part & 19 & $2826-8$ & 3.78 \\
\hline L gyrus rectus & 28 & $-1229-20$ & 3.70 \\
\hline L inferior frontal gyrus, orbital part & 30 & $-4626-8$ & 3.68 \\
\hline R caudate nucleus & 15 & 101116 & 3.61 \\
\hline R superior occipital gyrus & 19 & $28-9618$ & 3.60 \\
\hline L middle frontal gyrus & 21 & -401744 & 3.55 \\
\hline L middle frontal gyrus, orbital part & 36 & $-2152-13$ & 3.52 \\
\hline L middle frontal gyrus, orbital part & 51 & $-3450-8$ & 3.49 \\
\hline L inferior temporal gyrus & 9 & $-52-28-20$ & 3.49 \\
\hline R middle cingulate gyrus & 51 & $3-3632$ & 3.48 \\
\hline L angular gyrus & 37 & $-38-6632$ & 3.48 \\
\hline L inferior frontal gyrus, triangular part & 18 & -38232 & 3.48 \\
\hline Linsula & 26 & $-2816-8$ & 3.45 \\
\hline L inferior frontal gyrus, orbital part & 7 & $-1214-30$ & 3.45 \\
\hline L middle temporal gyrus & 22 & $-69-32-2$ & 3.44 \\
\hline L angular gyrus & 26 & $-46-5023$ & 3.42 \\
\hline R anterior cingulate gyrus & 8 & $828-7$ & 3.40 \\
\hline R superior frontal gyrus, medial part & 6 & 3595 & 3.38 \\
\hline Rinsula & 8 & $3017-19$ & 3.36 \\
\hline L middle frontal gyrus & 11 & -382344 & 3.36 \\
\hline R middle frontal gyrus & 7 & 444011 & 3.35 \\
\hline L inferior temporal gyrus & 10 & $-54-40-18$ & 3.31 \\
\hline R inferior temporal gyrus & 9 & $50-1-34$ & 3.27 \\
\hline L middle cingulate gyrus & 9 & $-8-4334$ & 3.27 \\
\hline L middle temporal gyrus & 9 & $-63-34-16$ & 3.23 \\
\hline
\end{tabular}

*Peaks that are $<0.05$, whole-brain FWE corrected.

food items, nor with the change in the difference between WTP for food vs nonfood items (all $|R|<0.31$, all $p>0.11$ ). For hunger ratings, the change from habitual sleep to sleep deprivation neither correlated with the change in total nor in acyl ghrelin (all $|R|<0.26$, all $p>0.18$ ). The change in des-acyl ghrelin from habitual sleep to sleep deprivation revealed a significant negative correlation with the change in hunger ratings $(r=-0.42, p=0.02)$. However, this correlation did not survive correction for multiple comparisons. When regarding only the individual sessions, there was no significant correlation between hunger ratings and des-acyl ghrelin values in the sleep deprivation session $(r=0.12, p=$ $0.53)$, compared with in the habitual sleep session $(r=-0.48, p=0.009)$. Concerning fMRI effects, the change in ghrelin between states neither correlated with activation in the above reported peaks for valuation, image onset-related activity, nor coupling (all $|R|<0.34$, all $p>0.07$ ).

Because leptin is also a key player in hunger regulation, we repeated the abovementioned correlation analyses of behavioral and fMRI data also with leptin as an additional exploratory analysis requested by one reviewer. Similar to ghrelin, leptin was also not correlated with the changes between sessions in WTP for food items only $(r=-0.004, p=0.98)$, nor with the change of the difference between WTP for food and nonfood items $(r=0.06, p=0.77)$, nor with hunger ratings $(r=-0.06, p=0.76)$. For fMRI, the change in leptin between session did neither correlate with activation in peaks for valuation, image onset-related activity, nor coupling (all $|\mathrm{R}|<0.32$, all $p>0.09$ ).

Finally, in an exploratory analysis, we combined all noncorrelated hormone parameters (see Materials and Methods) in a multiple regression analysis to test the association of the sleep $\times$ category interaction effects with changes in hormone parameters. The fMRI activations for valuation, image onset-related activity, and coupling were not significantly predicted by hormonal change scores (all $p \geq 0.10$ ).

\section{Discussion}

We found that, compared with a night of habitual sleep, a full night of sleep deprivation selectively increased the subjective valuation of snack food rewards compared with nonfood rewards. This result was paralleled by increased amygdala and hypothalamus activity selectively after sleep deprivation in response to food image onsets or their parametrical modulation by value. Furthermore, functional connectivity between amygdala and hypothalamus was increased after sleep deprivation specifically for food versus nonfood rewards. However, we found no evidence for a hormonal modulation of activity in these regions in response to food rewards after sleep deprivation.

We used a well established paradigm from behavioral economics (Becker et al., 1964) that has been repeatedly applied in conjunction with both food and nonfood rewards and fMRI (Plassmann et al., 2007; Chib et al., 2009; Suzuki et al., 2017). Consistent with previous work (Chib et al., 2009), vmPFC activation tracked subjective valuation of both food and nonfood rewards. Our results show similar valuation effects in vmPFC across reward categories and sleep states, whereas previous studies observed sleep-deprivation-dependent decreases in value representations in vmPFC for risky monetary rewards (Menz et al., 2012) or increases in social value signals in vmPFC (Libedinsky et al., 2011). However, in contrast to these earlier studies, here, participants were highly deprived of the tested reinforcer, which likely explains variable vmPFC results between studies. Moreover, our finding of selective hypothalamic valuation changes for 
Table 2. Brain regions where valuation signal activation selectively increased for food compared with nonfood rewards after sleep deprivation compared with habitual sleep for $p<0.001$, uncorrected, with at least 5 contiguous voxels; none of the peaks survived whole-brain FWE correction

\begin{tabular}{llll}
\hline Region & Cluster size & MNI coordinates $(x, y, z)$ & $z$-value \\
\hline L parahippocampal gyrus & 15 & $-10-16-22$ & 3.89 \\
R gyrus rectus & 9 & $1628-12$ & 3.46 \\
R middle frontal gyrus, orbital part & 5 & $1642-13$ & 3.35 \\
R middle frontal gyrus & 5 & 27441 & 3.32 \\
R hypothalamus & 7 & $4-1-10$ & 3.27 \\
\hline
\end{tabular}

\begin{tabular}{|c|c|c|c|}
\hline Region & Cluster size & MNI coordinates $(x, y, z)$ & $z$-value \\
\hline L middle temporal gyrus & 115 & $-366-30$ & 4.19 \\
\hline L superior frontal gyrus, medial part & 97 & -93238 & 4.13 \\
\hline L gyrus rectus & 44 & $-1623-12$ & 4.12 \\
\hline L posterior cingulate gyrus & 65 & $-10-4424$ & 3.99 \\
\hline L precuneus & 281 & $-6-6246$ & 3.89 \\
\hline $\mathrm{R} / \mathrm{L}$ superior frontal gyrus, medial part & 79 & 33041 & 3.82 \\
\hline R superior temporal pole & 51 & $3411-28$ & 3.80 \\
\hline R middle temporal gyrus & 34 & $66-10-24$ & 3.77 \\
\hline L superior temporal gyrus & 24 & $-36-26-1$ & 3.77 \\
\hline L hippocampus & 13 & $-30-28-8$ & 3.75 \\
\hline L superior frontal gyrus & 28 & -145638 & 3.73 \\
\hline R anterior cingulate gyrus & 14 & 92416 & 3.65 \\
\hline L posterior cingulate gyrus & 13 & $-9-3220$ & 3.63 \\
\hline L precuneus & 13 & $-15-434$ & 3.61 \\
\hline L middle frontal gyrus & 24 & -344217 & 3.60 \\
\hline L anterior cingulate gyrus & 33 & -83014 & 3.58 \\
\hline L superior frontal gyrus, medial part & 15 & -22642 & 3.56 \\
\hline L parahippocampal gyrus & 31 & $-6-22-25$ & 3.53 \\
\hline L anterior cingulate gyrus & 26 & -44217 & 3.51 \\
\hline L inferior parietal lobule & 17 & $-45-4856$ & 3.50 \\
\hline L middle cingulate gyrus & 30 & $-6-4240$ & 3.49 \\
\hline L posterior cingulate gyrus & 15 & $-9-3430$ & 3.49 \\
\hline Ramygdala & 20 & $20-2-25$ & 3.48 \\
\hline L middle temporal gyrus & 7 & $-52-40-10$ & 3.45 \\
\hline R thalamus & 6 & $6-13-2$ & 3.39 \\
\hline R hippocampus & 7 & $20-370$ & 3.39 \\
\hline L middle frontal gyrus & 13 & -401641 & 3.31 \\
\hline L hippocampus & 6 & $-26-7-26$ & 3.29 \\
\hline L postcentral gyrus & 6 & $-52-824$ & 3.21 \\
\hline R angular gyrus & 5 & $42-6041$ & 3.19 \\
\hline
\end{tabular}

food reward following sleep loss outlines a mechanism through which food cues might gain access to hypothalamic processing specifically in the sleep-deprived state. Further, the BDM food valuation task contained a nonfood control condition that allowed us to account for general differences in brain reward responsivity after sleep deprivation, complementing and extending previous literature on sleep deprivation and food reward processing (Benedict et al., 2012; Greer et al., 2013).

\section{Role of homeostatic hormones in food valuation after sleep deprivation}

Our experimental approach allowed for a combined investigation of hormonal, behavioral, and neural underpinnings of food reward processing following sleep loss. Although a hormonal account of sleep loss-induced overeating is controversial (Spiegel et al., 2004; Chaput and St-Onge, 2014), none of the previous studies investigating sleep deprivation in combination with food
Table 4. Brain regions coupled with right amygdala where BOLD activation related to stimulus onset increased for food compared with nonfood images after sleep deprivation compared with habitual sleep for $p<\mathbf{0 . 0 0 1}$, uncorrected, with at least 5 contiguous voxels; none of the peaks survived whole-brain FWE correction

\begin{tabular}{lcll}
\hline Region & Cluster size & MNI coordinates $(x, y, z)$ & $z$-value \\
\hline L fusiform gyrus & 60 & $-24-36-22$ & 4.89 \\
L posterior orbitofrontal cortex & 196 & $-2629-16$ & 4.81 \\
L middle frontal gyrus & 181 & -442830 & 4.25 \\
L thalamus & 25 & $-14-16-8$ & 3.97 \\
L precuneus & 29 & $-10-5012$ & 3.85 \\
R thalamus & 20 & $6-12-12$ & 3.84 \\
L anterior cingulate gyrus & 46 & -83528 & 3.81 \\
R insula & 70 & $2616-14$ & 3.75 \\
L middle cingulate gyrus & 16 & $-3-1330$ & 3.73 \\
R angular gyrus & 17 & $34-4235$ & 3.69 \\
R parahippocampal gyrus & 15 & $18-36-6$ & 3.68 \\
L hypothalamus & 16 & $-8-8-12$ & 3.67 \\
R precuneus & 10 & $22-5434$ & 3.65 \\
R insula & 14 & $3610-13$ & 3.52 \\
R middle temporal gyrus & 48 & $39-6614$ & 3.49 \\
L lobule IV, V of cerebellar hemisphere & 15 & $-9-52-24$ & 3.48 \\
L hippocampus & 12 & $-34-16-12$ & 3.47 \\
R posterior orbitofrontal cortex & 25 & $2624-16$ & 3.46 \\
L middle occipital gyrus & 14 & $-46-7817$ & 3.43 \\
L middle frontal gyrus & 10 & -264028 & 3.40 \\
L parahippocampal gyrus & 8 & $-27-16-24$ & 3.38 \\
R middle cingulate gyrus & 6 & $3-3834$ & 3.37 \\
L superior frontal gyrus & 5 & -201236 & 3.32 \\
L middle cingulate gyrus & 7 & $-8-3434$ & 3.24 \\
R middle temporal gyrus & 6 & $44-6620$ & 3.21 \\
L middle temporal gyrus & 6 & $-46-38-6$ & 3.18 \\
\hline & & & \\
\hline
\end{tabular}

stimuli controlled for endocrine effects on BOLD activity (Benedict et al., 2012; St-Onge et al., 2012; Greer et al., 2013) despite the suggested association between ghrelin and neural food reward responses (Malik et al., 2008; Kroemer et al., 2013; Goldstone et al., 2014) based in part on the known effects of ghrelin on dopamine release (Jerlhag et al., 2006, 2007; Jerlhag, 2008).

As expected, we observed increases in circulating des-acyl ghrelin after sleep deprivation compared with habitual sleep, whereas total and acyl ghrelin levels were not significantly different between conditions. The strong positive between-session correlation of all hormone parameters except glucose indicates the reliability of the laboratory methods and a trait-like stability of the endocrine parameters, with a potential modulation by sleep state only in the case of des-acyl ghrelin. Initially, acyl ghrelin was thought to be the biological active hormone that binds to the GHSR-1s receptor, whereas des-acyl ghrelin was thought to be an inactive degradation product of acyl ghrelin (Kojima et al., 1999). Although this view has recently been questioned (Delhanty et al., 2012, 2014; Müller et al., 2015), potential mechanisms of action of des-acyl ghrelin still need to be elucidated. Additionally, the interpretation of our results is complicated by the inconsistent use of the different ghrelin parameters in previous studies, focusing on total (Schmid et al., 2008), acyl (Goldstone et al., 2014), or des-acyl ghrelin (Kroemer et al., 2013) or on growth hormone assessment (Malik et al., 2008).

Contrary to our hypothesis, changes between sessions in ghrelin were not correlated with changes in fMRI activity. In addition to the absence of associations between changes in ghrelin levels and behavior, this result further argues against a hormonal account of effects of sleep loss on food intake (Chaput and St-Onge, 2014; Cedernaes et al., 2015). One potential explanation might be a ceiling effect of homeostatic hunger in both conditions. We 

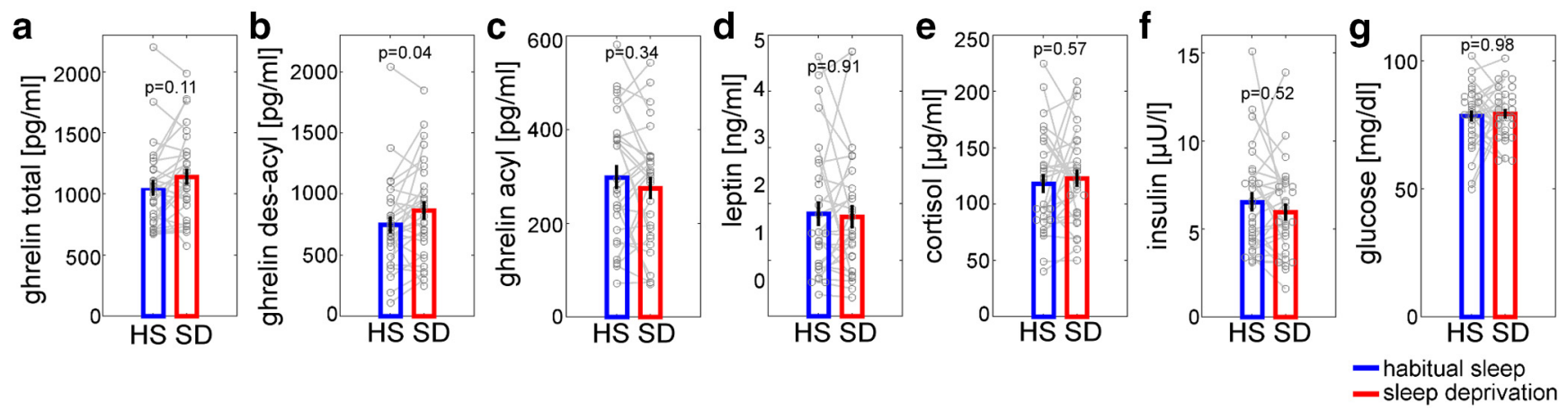

Figure 7. Endocrine raw data. Shown are blood plasma concentrations of total ghrelin (a), des-acyl ghrelin (b), and acyl ghrelin (c), as well as blood serum concentrations of leptin (d), cortisol $(\boldsymbol{e})$, insulin $(\boldsymbol{f})$, and glucose $(\boldsymbol{g})$. The difference in blood levels between states was only significant for des-acyl ghrelin $(z=-2.07, p=0.04)$.

Table 5. Raw endocrine parameter concentrations after habitual sleep and a full night of sleep deprivation

\begin{tabular}{lccrl}
\hline Endocrine parameter & Habitual sleep & Sleep deprivation & $z$-value & $p$-value \\
\hline Ghrelin total $(\mathrm{pg} / \mathrm{ml})$ & $1048.14 \pm 61.54$ & $1140.94 \pm 64.37$ & -1.59 & 0.11 \\
Ghrelin acyl $(\mathrm{pg} / \mathrm{ml})$ & $298.60 \pm 24.92$ & $275.33 \pm 23.03$ & 0.96 & 0.34 \\
Ghrelin des-acyl $(\mathrm{pg} / \mathrm{ml})$ & $749.54 \pm 69.06$ & $865.61 \pm 73.73$ & -2.07 & $0.039^{*}$ \\
Leptin $(\mathrm{ng} / \mathrm{ml})$ & $1.82 \pm 0.21$ & $1.77 \pm 0.20$ & 0.12 & 0.91 \\
Cortisol $(\mu \mathrm{g} / \mathrm{L})$ & $118.00 \pm 8.09$ & $122.90 \pm 7.49$ & -0.56 & 0.57 \\
Insulin $(\mu \mathrm{U} / \mathrm{ml})$ & $6.53 \pm 0.53$ & $5.96 \pm 0.47$ & 0.65 & 0.52 \\
Glucose $(\mathrm{mg} / \mathrm{dl})$ & $78.48 \pm 2.14$ & $79.38 \pm 1.86$ & -0.02 & 0.98 \\
HOMA-IR & $1.29 \pm 0.12$ & $1.18 \pm 0.10$ & 0.77 & 0.44
\end{tabular}

Shown are total, acyl, and des-acyl ghrelin as well as leptin, cortisol, insulin, and glucose concentrations after a full night of habitual sleep or total sleep deprivation for 29 participants. $z$-values are from nonparametric Wilcoxon signed-rank tests. Data are shown as mean \pm SEM.

${ }^{*} p<0.05$.

found substantially higher average total and des-acyl ghrelin levels in both conditions compared with previous studies (Schmid et al., 2008; Kroemer et al., 2013). These differences might be due to a longer fasting interval in our approach, which could increase hunger to a ceiling level, as well as standardized dinner consumption. Moreover, in contrast to Schmid et al. (2008), participants were allowed to freely move during sleep deprivation. However, previous studies found no effect of exercise on des-acyl ghrelin concentrations (Shiiya et al., 2011) and mixed effects on total ghrelin levels (Burns et al., 2007; Toshinai et al., 2007; Jürimäe et al., 2009).

We found involvement of the hypothalamus, which regulates hunger (Anand and Brobeck, 1951) and circadian rhythm (Economo, 1930), in food valuation after sleep deprivation. This suggests a possible sleep-deprivation-dependent switch from hedonic reward systems to homeostatic systems for food valuation.

Our work replicates previous results (Sun et al., 2015) building upon findings of cue-potentiated feeding (Weingarten, 1983), which demonstrated amygdala activity in response to food cues in a sated state. In our dataset, as in Sun et al. (2015), ghrelin did not modulate amygdala-hypothalamus interactions, which might reflect an increased hedonic rather than hormonal mechanism. However, if homeostasis-related hormones play a lesser role, what might drive the amygdala-hypothalamic circuit following sleep loss? Hedonic factors (e.g., the opioid system; Levine and Billington, 2004) or alterations in dopamine transmission (Volkow et al., 2008, 2012) might additionally contribute to increased food valuation after sleep loss.

\section{Limitations}

Although previous studies observed effects of sleep deprivation on ghrelin concentrations in smaller samples (Spiegel et al., 2004;
Schmid et al., 2008; Hogenkamp et al., 2013), potential interaction effects between ghrelin and food valuation might be more subtle. Larger samples in future studies might help to avoid potential problems such as underpowered analyses.

Consistent with previous findings (Ratcliff and Van Dongen, 2009, 2011; Menz et al., 2012), our DDM analyses using a regression approach revealed attenuated conflict-dependent changes in drift rate following sleep deprivation. However, DDM parameters did not show differential effects for food versus nonfood rewards, suggesting that choice dynamics were affected by sleep deprivation, but not in a category-specific fashion. Despite a nonoptimized design due to minimum waiting periods before response logging, we observed effects of sleep deprivation similar to previous studies (Ratcliff and Van Dongen, 2009, 2011; Menz et al., 2012).

Dinner serving sizes were standardized but not adapted to basal metabolic rates of the participants. To avoid confounds due to different metabolic rates, future studies might adapt serving sizes based on basal metabolic rates (Harris and Benedict, 1918).

Recent studies recommended distortion correction before T1-based normalization (Calhoun et al., 2017), which was not performed in our study. However, additional control analyses revealed reduced sensitivity for valuation signals in vmPFC in the present dataset when using EPI-template based normalization as recommended by Calhoun et al. (2017) rather than T1-based normalization using unified segmentation. Nonetheless, future studies might benefit from obtaining field maps to improve sensitivity (Calhoun et al., 2017).

One problem of modern society is sleep restriction that builds up constantly over a week of work (McCoy and Strecker, 2011) rather than total sleep deprivation. However, in our approach, we used a total night of using sleep deprivation as a first step in unraveling mechanisms underlying sleep-loss-associated increased food valuation. Potential differences in the effects of partial and total sleep deprivation on homeostasis-related processes should be explored directly in future studies.

A final limitation of our study is the lack of reliable objective measures for sleep quality and quantity because only actigraphy was applied to monitor sleep duration before habitual sleep sessions in combination with a questionnaire-based assessment of general sleep quality, instead of detailed monitoring via polysomnography. Future studies might use more reliable objective sleep measures to control sleep quality and quantity and to explore a potential active role of sleep quality in modulating homeostasisrelated processes. 


\section{Conclusion}

The link between sleep loss and obesity is well established by various meta-analyses (Sperry et al., 2015; Capers et al., 2015). Although the extent of the contribution of hormonal and hedonic factors to this phenomenon is a matter of ongoing controversy (Chaput and St-Onge, 2014; Cedernaes et al., 2015), to our knowledge, no other study has combined a within-subject sleep deprivation paradigm including value-based food decision making under realistic everyday life conditions with adequate nonfood control stimuli, brain activation, and homeostatic hormone concentrations. By using these methods, we revealed a mechanism through which sleep deprivation might promote food intake by enabling food cues to gain access to processing in hypothalamic circuits via the amygdala. This might then drive a food-specific increase in behavioral valuation as well as hypothalamic representations of value, thereby potentially increasing the likelihood of overeating and consequentially weight gain and obesity risk.

\section{References}

Anand BK, Brobeck JR (1951) Localization of a "feeding center" in the hypothalamus of the rat. Proc Soc Exp Biol Med 77:323-324. CrossRef Medline

Bartra O, McGuire JT, Kable JW (2013) The valuation system: a coordinatebased meta-analysis of bold fMRI experiments examining neural correlates of subjective value. Neuroimage 76:412-427. CrossRef Medline

Becker GM, DeGroot MH, Marschak J (1964) Measuring utility by a singleresponse sequential method. Behav Sci 9:226-232. CrossRef Medline

Benedict C, Brooks SJ, O’Daly OG, Almèn MS, Morell A, Åberg K, Gingnell M, Schultes B, Hallschmid M, Broman JE, Larsson EM, Schiöth HB (2012) Acute sleep deprivation enhances the brain's response to hedonic food stimuli: an fMRI study. J Clin Endocrinol Metab 97:E443-447. CrossRef Medline

Burns SF, Broom DR, Miyashita M, Mundy C, Stensel DJ (2007) A single session of treadmill running has no effect on plasma total ghrelin concentrations. J Sports Sci 25:635-642. CrossRef Medline

Buysse DJ, Reynolds CF 3rd, Monk TH, Berman SR, Kupfer DJ (1989) The Pittsburgh sleep quality index: a new instrument for psychiatric practice and research. Psychiatry Res 28:193-213. CrossRef Medline

Calhoun VD, Wager TD, Krishnan A, Rosch KS, Seymour KE, Nebel MB, Mostofsky SH, Nyalakanai P, Kiehl K (2017) The impact of T1 versus EPI spatial normalization templates for fMRI data analyses. Hum Brain Mapp 38:5331-5342. CrossRef Medline

Capers PL, Fobian AD, Kaiser KA, Borah R, Allison DB (2015) A systematic review and meta-analysis of randomized controlled trials of the impact of sleep duration on adiposity and components of energy balance. Obes Rev 16:771-782. CrossRef Medline

Cavanagh JF, Wiecki TV, Cohen MX, Figueroa CM, Samanta J, Sherman SJ, Frank MJ (2011) Subthalamic nucleus stimulation reverses mediofrontal influence over decision threshold. Nat Neurosci 14:1462-1467. CrossRef Medline

Cedernaes J, Schiöth HB, Benedict C (2015) Determinants of shortened, disrupted, and mistimed sleep and associated metabolic health consequences in healthy humans. Diabetes 64:1073-1080. CrossRef Medline

Chaput JP, St-Onge MP (2014) Increased food intake by insufficient sleep in humans: are we jumping the gun on the hormonal explanation? Front Endocrinol (Lausanne) 5:116. CrossRef Medline

Chib VS, Rangel A, Shimojo S, O’Doherty JP (2009) Evidence for a common representation of decision values for dissimilar goods in human ventromedial prefrontal cortex. J Neurosci 29:12315-12320. CrossRef Medline

Clithero JA, Rangel A (2014) Informatic parcellation of the network involved in the computation of subjective value. Soc Cogn Affect Neurosci 9:1289-1302. CrossRef Medline

Cournot M, Ruidavets JB, Marquié JC, Esquirol Y, Baracat B, Ferrières J (2004) Environmental factors associated with body mass index in a population of southern France. Eur J Cardiovasc Prev Rehabil 11:291-297. CrossRef Medline

D'Agostino AE, Small DM (2012) Neuroimaging the interaction of mind and metabolism in humans. Mol Metab 1:10-20. CrossRef Medline

Delhanty PJ, Neggers SJ, van der Lely AJ (2012) Mechanisms in endocrinol- ogy: ghrelin: the differences between acyl- and des-acyl ghrelin. Eur J Endocrinol 167:601-608. CrossRef Medline

Delhanty PJ, Neggers SJ, van der Lely AJ (2014) Should we consider des-acyl ghrelin as a separate hormone and if so, what does it do? Front Horm Res 42:163-174. CrossRef Medline

Economo CV (1930) Sleep as a problem of localization. J Nerv Ment Dis 71:249. CrossRef

Feinberg DA, Moeller S, Smith SM, Auerbach E, Ramanna S, Gunther M, Glasser MF, Miller KL, Ugurbil K, Yacoub E (2010) Multiplexed echo planar imaging for sub-second whole brain fmri and fast diffusion imaging. PLoS One 5:e15710. CrossRef Medline

Friston KJ, Buechel C, Fink GR, Morris J, Rolls E, Dolan RJ (1997) Psychophysiological and modulatory interactions in neuroimaging. Neuroimage 6:218-229. CrossRef Medline

Gelman A, Carlin JB, Stern HS, Dunson DB, Vehtari A, Rubin DB (2013) Bayesian Data Analysis, Third Edition. London: Taylor \& Francis.

Gluth S, Sommer T, Rieskamp J, Büchel C (2015) Effective connectivity between hippocampus and ventromedial prefrontal cortex controls preferential choices from memory. Neuron 86:1078-1090. CrossRef Medline

Goldstone AP, Prechtl CG, Scholtz S, Miras AD, Chhina N, Durighel G, Deliran SS, Beckmann C, Ghatei MA, Ashby DR, Waldman AD, Gaylinn BD, Thorner MO, Frost GS, Bloom SR, Bell JD (2014) Ghrelin mimics fasting to enhance human hedonic, orbitofrontal cortex, and hippocampal responses to food. Am J Clin Nutr 99:1319-1330. CrossRef Medline

Greer SM, Goldstein AN, Walker MP (2013) The impact of sleep deprivation on food desire in the human brain. Nat Commun 4:2259. CrossRef Medline

Griswold MA, Jakob PM, Heidemann RM, Nittka M, Jellus V, Wang J, Kiefer B, Haase A (2002) Generalized autocalibrating partially parallel acquisitions (GRAPPA). Magn Reson Med 47:1202-1210. CrossRef Medline

Harris JA, Benedict FG (1918) A biometric study of human basal metabolism. Proc Natl Acad Sci U S A 4:370-373. CrossRef Medline

Herz DM, Zavala BA, Bogacz R, Brown P (2016) Neural correlates of decision thresholds in the human subthalamic nucleus. Curr Biol 26:916-920. CrossRef Medline

Heslop P, Smith GD, Metcalfe C, Macleod J, Hart C (2002) Sleep duration and mortality: the effect of short or long sleep duration on cardiovascular and all-cause mortality in working men and women. Sleep Med 3:305314. CrossRef Medline

Hogenkamp PS, Nilsson E, Nilsson VC, Chapman CD, Vogel H, Lundberg LS, Zarei S, Cedernaes J, Rångtell FH, Broman JE, Dickson SL, Brunstrom JM, Benedict C, Schiöth HB (2013) Acute sleep deprivation increases portion size and affects food choice in young men. Psychoneuroendocrinology 38:1668-1674. CrossRef Medline

Howard AD, Feighner SD, Cully DF, Arena JP, Liberator PA, Rosenblum CI, Hamelin M, Hreniuk DL, Palyha OC, Anderson J, Paress PS, Diaz C, Chou M, Liu KK, McKee KK, Pong SS, Chaung LY, Elbrecht A, Dashkevicz M, Heavens R, et al. (1996) A receptor in pituitary and hypothalamus that functions in growth hormone release. Science 273:974-977. CrossRef Medline

Jerlhag E (2008) Systemic administration of ghrelin induces conditioned place preference and stimulates accumbal dopamine. Addict Biol 13:358 363. CrossRef Medline

Jerlhag E, Egecioglu E, Dickson SL, Andersson M, Svensson L, Engel JA (2006) Ghrelin stimulates locomotor activity and accumbal dopamineoverflow via central cholinergic systems in mice: implications for its involvement in brain reward. Addict Biol 11:45-54. CrossRef Medline

Jerlhag E, Egecioglu E, Dickson SL, Douhan A, Svensson L, Engel JA (2007) Ghrelin administration into tegmental areas stimulates locomotor activity and increases extracellular concentration of dopamine in the nucleus accumbens. Addict Biol 12:6-16. CrossRef Medline

Jürimäe J, Rämson R, Mäestu J, Purge P, Jürimäe T, Arciero PJ, von Duvillard SP (2009) Plasma visfatin and ghrelin response to prolonged sculling in competitive male rowers. Med Sci Sports Exerc 41:137-143. CrossRef Medline

Kojima M, Hosoda H, Date Y, Nakazato M, Matsuo H, Kangawa K (1999) Ghrelin is a growth-hormone-releasing acylated peptide from stomach. Nature 402:656-660. CrossRef Medline

Kroemer NB, Krebs L, Kobiella A, Grimm O, Pilhatsch M, Bidlingmaier M, Zimmermann US, Smolka MN (2013) Fasting levels of ghrelin covary 
with the brain response to food pictures. Addict Biol 18:855-862. CrossRef Medline

Kullmann S, Heni M, Veit R, Scheffler K, Machann J, Häring HU, Fritsche A, Preissl H (2015) Selective insulin resistance in homeostatic and cognitive control brain areas in overweight and obese adults. Diabetes Care 38:1044-1050. CrossRef Medline

Levine AS, Billington CJ (2004) Opioids as agents of reward-related feeding: a consideration of the evidence. Physiol Behav 82:57-61. CrossRef Medline

Libedinsky C, Smith DV, Teng CS, Namburi P, Chen VW, Huettel SA, Chee MW (2011) Sleep deprivation alters valuation signals in the ventromedial prefrontal cortex. Front Behav Neurosci 5:70. Medline

Maldjian JA, Laurienti PJ, Kraft RA, Burdette JH (2003) An automated method for neuroanatomic and cytoarchitectonic atlas-based interrogation of fMRI data sets. Neuroimage 19:1233-1239. CrossRef Medline

Maldjian JA, Laurienti PJ, Burdette JH (2004) Precentral gyrus discrepancy in electronic versions of the Talairach atlas. Neuroimage 21:450-455. CrossRef Medline

Malik S, McGlone F, Bedrossian D, Dagher A (2008) Ghrelin modulates brain activity in areas that control appetitive behavior. Cell Metab 7:400409. CrossRef Medline

Matthews DR, Hosker JP, Rudenski AS, Naylor BA, Treacher DF, Turner RC (1985) Homeostasis model assessment: insulin resistance and $\beta$-cell function from fasting plasma glucose and insulin concentrations in man. Diabetologia 28:412-419. CrossRef Medline

McCoy JG, Strecker RE (2011) The cognitive cost of sleep lost. Neurobiol Learn Mem 96:564-582. CrossRef Medline

Menz MM, Büchel C, Peters J (2012) Sleep deprivation is associated with attenuated parametric valuation and control signals in the midbrain during value-based decision making. J Neurosci 32:6937-6946. CrossRef Medline

Milosavljevic M, Malmaud J, Huth A, Koch C, Rangel A (2010) The drift diffusion model can account for value-based choice response times under high and low time pressure. Judgment and Decision Making 5:437-449.

Moeller S, Yacoub E, Olman CA, Auerbach E, Strupp J, Harel N, Uğurbil K (2010) Multiband multislice GE-EPI at 7 tesla, with 16-fold acceleration using partial parallel imaging with application to high spatial and temporal whole-brain fMRI. Magn Reson Med 63:1144-1153. CrossRef Medline

Morselli L, Leproult R, Balbo M, Spiegel K (2010) Role of sleep duration in the regulation of glucose metabolism and appetite. Best Pract Res Clin Endocrinol Metab 24:687-702. CrossRef Medline

Müller TD, Nogueiras R, Andermann ML, Andrews ZB, Anker SD, Argente J, Batterham RL, Benoit SC, Bowers CY, Broglio F, Casanueva FF, D'Alessio D, Depoortere I, Geliebter A, Ghigo E, Cole PA, Cowley M, Cummings DE, Dagher A, Diano S, et al. (2015) Ghrelin. Mol Metab 4:437-460. CrossRef Medline

Patel SR, Hu FB (2008) Short sleep duration and weight gain: a systematic review. Obesity 16:643-653. CrossRef Medline

Plassmann H, O’Doherty J, Rangel A (2007) Orbitofrontal cortex encodes willingness to pay in everyday economic transactions. J Neurosci 27: 9984-9988. CrossRef Medline

Rangel A (2013) Regulation of dietary choice by the decision-making circuitry. Nat Neurosci 16:1717-1724. CrossRef Medline

Ratcliff R, McKoon G (2008) The diffusion decision model: theory and data for two-choice decision tasks. Neural Comput 20:873-922. CrossRef Medline

Ratcliff R, Van Dongen HP (2009) Sleep deprivation affects multiple distinct cognitive processes. Psychon Bull Rev 16:742-751. CrossRef Medline

Ratcliff R, Van Dongen HP (2011) Diffusion model for one-choice reaction-time tasks and the cognitive effects of sleep deprivation. Proc Natl Acad Sci U S A 108:11285-11290. CrossRef Medline
Rontoyanni VG, Baic S, Cooper AR (2007) Association between nocturnal sleep duration, body fatness, and dietary intake in greek women. Nutrition 23:773-777. CrossRef Medline

Schmid SM, Hallschmid M, Jauch-Chara K, Born J, Schultes B (2008) A single night of sleep deprivation increases ghrelin levels and feelings of hunger in normal-weight healthy men. J Sleep Res 17:331-334. CrossRef Medline

Schwartz MW, Seeley RJ, Campfield LA, Burn P, Baskin DG (1996) Identification of targets of leptin action in rat hypothalamus. J Clin Invest 98:1101-1106. CrossRef Medline

Setsompop K, Gagoski BA, Polimeni JR, Witzel T, Wedeen VJ, Wald LL (2012) Blipped-controlled aliasing in parallel imaging for simultaneous multislice echo planar imaging with reduced g-factor penalty. Magn Reson Med 67:1210-1224. CrossRef Medline

Shigeta H, Shigeta M, Nakazawa A, Nakamura N, Yoshikawa T (2001) Lifestyle, obesity, and insulin resistance. Diabetes Care 24:608. Medline

Shiiya T, Ueno H, Toshinai K, Kawagoe T, Naito S, Tobina T, Nishida Y, Shindo M, Kangawa K, Tanaka H, Nakazato M (2011) Significant lowering of plasma ghrelin but not des-acyl ghrelin in response to acute exercise in men. Endocr J 58:335-342. CrossRef Medline

Sperry SD, Scully ID, Gramzow RH, Jorgensen RS (2015) Sleep duration and waist circumference in adults: a meta-analysis. Sleep 38:1269-1276. CrossRef Medline

Spiegel K, Tasali E, Penev P, Van Cauter E (2004) Brief communication: sleep curtailment in healthy young men is associated with decreased leptin levels, elevated ghrelin levels, and increased hunger and appetite. Ann Intern Med 141:846-850. CrossRef Medline

St-Onge MP, McReynolds A, Trivedi ZB, Roberts AL, Sy M, Hirsch J (2012) Sleep restriction leads to increased activation of brain regions sensitive to food stimuli. Am J Clin Nutr 95:818-824. CrossRef Medline

Sun X, Kroemer NB, Veldhuizen MG, Babbs AE, de Araujo IE, Gitelman DR, Sherwin RS, Sinha R, Small DM (2015) Basolateral amygdala response to food cues in the absence of hunger is associated with weight gain susceptibility. J Neurosci 35:7964-7976. CrossRef Medline

Suzuki S, Cross L, O’Doherty JP (2017) Elucidating the underlying components of food valuation in the human orbitofrontal cortex. Nat Neurosci 20:1780-1786. CrossRef Medline

Taheri S, Lin L, Austin D, Young T, Mignot E (2004) Short sleep duration is associated with reduced leptin, elevated ghrelin, and increased body mass index. PLoS Med 1:e62. CrossRef Medline

Toshinai K, Kawagoe T, Shimbara T, Tobina T, Nishida Y, Mondal MS, Yamaguchi H, Date Y, Tanaka H, Nakazato M (2007) Acute incremental exercise decreases plasma ghrelin level in healthy men. Horm Metab Res 39:849-851. CrossRef Medline

Volkow ND, Wang GJ, Telang F, Fowler JS, Logan J, Wong C, Ma J, Pradhan K, Tomasi D, Thanos PK, Ferré S, Jayne M (2008) Sleep deprivation decreases binding of $[11 \mathrm{C}]$ Raclopride to dopamine D2/D3 receptors in the human brain. J Neurosci 28:8454-8461. CrossRef Medline

Volkow ND, Tomasi D, Wang GJ, Telang F, Fowler JS, Logan J, Benveniste H, Kim R, Thanos PK, Ferré S (2012) Evidence that sleep deprivation downregulates dopamine D2R in ventral striatum in the human brain. J Neurosci 32:6711-6717. CrossRef Medline

Voss A, Voss J, Lerche V (2015) Assessing cognitive processes with diffusion model analyses: a tutorial based on fast-dm-30. Front Psychol 6:336. CrossRef Medline

Weingarten HP (1983) Conditioned cues elicit feeding in sated rats: a role for learning in meal initiation. Science 220:431-433. CrossRef Medline

Wiecki TV, Sofer I, Frank MJ (2013) HDDM: hierarchical Bayesian estimation of the drift-diffusion model in Python. Front Neuroinform 7:14. CrossRef Medline

Xu J, Moeller S, Auerbach EJ, Strupp J, Smith SM, Feinberg DA, Yacoub E, Uğurbil K (2013) Evaluation of slice accelerations using multiband echo planar imaging at 3 T. Neuroimage 83:991-1001. CrossRef Medline 